\title{
Three-Input Single-Output Voltage-Mode Multifunction Filter with Electronic Controllability Based on Single Commercially Available IC
}

\author{
Supachai Klungtong, ${ }^{1}$ Dusit Thanapatay, ${ }^{1}$ and Winai Jaikla ${ }^{2}$ \\ ${ }^{1}$ Department of Electrical Engineering, Faculty of Engineering, Kasetsart University, Bangkok 10900, Thailand \\ ${ }^{2}$ Department of Engineering Education, Faculty of Industrial Education, King Mongkut's Institute of Technology Ladkrabang, \\ Bangkok 10520, Thailand
}

Correspondence should be addressed to Winai Jaikla; winai.ja@hotmail.com

Received 6 January 2017; Accepted 6 February 2017; Published 3 April 2017

Academic Editor: Jiun-Wei Horng

Copyright (C) 2017 Supachai Klungtong et al. This is an open access article distributed under the Creative Commons Attribution License, which permits unrestricted use, distribution, and reproduction in any medium, provided the original work is properly cited.

This paper presents a second-order voltage-mode filter with three inputs and single-output voltage using single commercially available IC, one resistor, and two capacitors. The used commercially available IC, called LT1228, is manufactured by Linear Technology Corporation. The proposed filter is based on parallel RLC circuit. The filter provides five output filter responses, namely, band-pass (BP), band-reject (BR), low-pass (LP), high-pass (HP), and all-pass (AP) functions. The selection of each filter response can be done without the requirement of active and passive component matching condition. Furthermore, the natural frequency and quality factor are electronically controlled. Besides, the nonideal case is also investigated. The output voltage node exhibits low impedance. The experimental results can validate the theoretical analyses.

\section{Introduction}

Analog filter is widely utilized in numerous applications such as communication, sound system, instrumentation, and control system. The biquadratic or second-order filter is the important building block. Also, this filter is the basic block to design high order filter. In particular, the second-order multifunction filter which provides many filter responses in the same circuit has gained significant attention and has become an interesting research topic [1,2]. The multiple-inputs singleoutput (MISO) universal filter is the interesting one and has been continuously proposed. In case of voltage-mode MISO filter, the selection of output filter response by switching on or off the input voltages should be done without the matching condition of passive and active elements. Moreover, the additional double gain amplifier should not be required.

Attention has been paid to the use of active building block in synthesis and design of electronic circuits for analog signal processing [3-6]. The active building block based circuits require a minimum number of active elements (most of them use only single active building block). Thus, the new active building blocks have been continuously introduced especially the electronically controllable active building block. Most of them are designed and constructed from BJT or CMOS transistors. Practically, these devices should be fabricated into the chip for the best way to test their performances. However, their performances and applications are often proved via simulation by only using computer program due to the investment cost reason. Although the new active building block can be constructed from commercially available IC, for example, in [7, 8] using AD844 and in [9] using OPA860 and EL2082, they still require more than one commercially available IC. Despite the fact that some circuits can use single AD844 as active building block, the AD844 based circuits are not electronically controlled.

In the literature, a number of multiple-input singleoutput voltage-mode multifunction filters based on different active building blocks have been reported in [10-42] and the references cited. However, the proposed filter in [10-16, 18$23,27,29,30,32,34,38,39,41,42]$ uses more than one active building block. The natural frequency and quality factor of 
the filters in $[10-17,19,21-25,27,28,30,32,35,38,39]$ are not electronically tuned. The matching condition for selection of output filter response is required for the circuit in $[14,15,17$, $21,23,26,28,33,35-38]$. The active building block used in $[19,24,27,30,32,36,38]$ is not commercially available IC. The output voltage node does not exhibit low impedance for the filter in $[11,12,14,15,17,18,20-22,24,25,29,31,33,34,36-$ $38,40]$. The proposed filter in $[37,41]$ requires double input signal. Additionally, only the proposed filters in [11-18, 21, 22, $25,26,31,35,39,41,42]$ are supported by the experimental measurements.

The three-input single-output voltage-mode biquad filter emphasizing the use of single commercially available IC, LT1228 from Linear Technology Inc., is present in this paper. The proposed filter consists of single LT1228, single resistor, and two capacitors which are suitable for off-the-shelf implementation. The selection of output filter response can be done without the requirement of any passive and active component matching condition. The natural frequency and quality factor can be electronically adjusted. The experimental results of proposed filter agree well with the theoretical expectation.

\section{Principle of Operation}

2.1. Active Building Block: LT1228. LT1228 is commercially manufactured by Linear Technology Inc. [43]. It is the combination of transconductance amplifier (OTA) and current feedback amplifier (CFA). The symbolic representation of LT1228 is shown in Figure 1(a). Let us denote the name of each port as $v_{+}, v_{-}, z, x$, and $w$. In ideal consideration, impedance at ports $v_{+}, v_{-}$, and $z$ exhibits high and the impedance at ports $x$ and $w$ exhibits low. Figure 1(b) shows the equivalent circuit and pin configuration is illustrated in Figure 1(c). Ideally, the port relation can be described by the following matrix:

$$
\left(\begin{array}{c}
I_{v_{+}} \\
I_{v_{-}} \\
I_{z} \\
V_{x} \\
V_{w}
\end{array}\right)=\left(\begin{array}{ccccc}
0 & 0 & 0 & 0 & 0 \\
0 & 0 & 0 & 0 & 0 \\
g_{m} & -g_{m} & 0 & 0 & 0 \\
0 & 0 & 1 & 0 & 0 \\
0 & 0 & 0 & R_{T} & 0
\end{array}\right)\left(\begin{array}{c}
V_{+} \\
V_{-} \\
V_{z} \\
I_{x} \\
I_{w}
\end{array}\right)
$$

where $R_{T}$ is the transresistance gain. In an ideal case, $R_{T}$ is typically very large and can be considered as infinite value. $g_{m}$ of LT1228 is controlled by DC bias current $I_{B}$ as follows:

$$
g_{m}=10 I_{B}
$$

2.2. Proposed Filter. The structure of three-input and singleoutput voltage-mode filter which is composed of single commercially available IC, single resistor, and two capacitors is presented in Figure 1. This filter is based on parallel RLC circuit. The input voltage $v_{\mathrm{in} 1}$ is applied at $v_{+}$terminal which is ideally high impedance, $v_{\mathrm{in} 2}$ is applied through $C_{1}$, and $v_{\text {in } 3}$ is applied through $R$. The output voltage $v_{\mathrm{o}}$ is at $x$ terminal which exhibits low impedance. In routine analysis, the output voltage of the proposed filter can be given as

$$
v_{\mathrm{o}}=\frac{v_{\mathrm{in} 1}\left(g_{m} / C_{1}\right) s+v_{\mathrm{in} 2} s^{2}+v_{\mathrm{in} 3}\left(g_{m} / C_{1} C_{2} R\right)}{s^{2}+\left(g_{m} / C_{1}\right) s+g_{m} / C_{1} C_{2} R} .
$$

From (3), the natural frequency is given as

$$
\omega_{0}=\sqrt{\frac{g_{m}}{C_{1} C_{2} R}}
$$

Subsequently, the quality factor is given as

$$
Q=\sqrt{\frac{C_{1}}{C_{2} g_{m} R}}
$$

It is evident from (4) and (5) that the natural frequency and quality factor can be electronically tuned via $g_{m}$.

It is found from (3) that the derivation of five filter responses can be done as follows:

(i) If the input voltage is applied at node $v_{\text {in } 3}$ while nodes $v_{\text {in } 1}$ and $v_{\text {in2 }}$ are grounded, the noninverting low-pass filter is achieved.

(ii) If the input voltage is applied at node $v_{\text {in2 }}$ while nodes $v_{\text {in } 1}$ and $v_{\text {in } 3}$ are grounded, the noninverting high-pass filter is achieved.

(iii) If the input voltage is applied at node $v_{\text {in } 1}$ while nodes $v_{\text {in2 }}$ and $v_{\text {in } 3}$ are grounded, the noninverting bandpass filter is achieved.

(iv) If the input voltage is applied at nodes $v_{\text {in } 2}$ and $v_{\text {in } 3}$ while node $v_{\text {in } 1}$ is grounded, the noninverting bandreject filter is achieved.

(v) If the input voltage is applied at nodes $v_{\text {in2 }}$ and $v_{\text {in } 3}$ while the inverting input voltage is applied at node $v_{\mathrm{in} 1}$, the noninverting all-pass filter is.

It is found from the above statement that the output filter response can be selected without the active and passive matching condition. Moreover, the all-pass filter response does not require the double gain amplifier circuit unlike the MISO filters in [37, 41]. However, the inverting unit gain amplifier circuit is required for the all-pass function [44].

\section{Effect of Parasitic Elements}

Practically, the influence of parasitic element in LT1228 will affect the performances of the proposed filter. High impedance ports $V_{+}, V_{-}$, and $z$ and the parallel RC appeared. The parasitic resistance and capacitance are, respectively, named as $R_{+}, C_{+}$, $R_{-}, C_{-}, R_{z}$, and $C_{z}$. At low impedance port $x$, the series resistance appears. This resistance is denoted as $R_{x}$. Also, the transresistance gain $\left(R_{T}\right)$ is considered as $R_{T}$ paralleled with $C_{T}$. These important parasitic impedances most affect the performance of the proposed circuit. Taking them into account, the output voltage of the circuit in Figure 2 is obtained as

$$
v_{\mathrm{o}}=\frac{g_{m}\left(Y_{T}+s C_{2}\right) v_{\mathrm{in} 1}+\left(Y_{T}+s C_{2}\right) s C_{1} v_{\mathrm{in} 2}+\left[R_{x} Y_{T}\left(Y_{z}+s C_{1}\right)+g_{m}\right] G v_{\mathrm{in} 3}}{\left\{\left(s C_{2}+G\right)\left[R_{x} Y_{T}\left(Y_{z}+s C_{1}\right)+g_{m}\right]\right\}+\left[\left(Y_{T}+s C_{2}\right)\left(Y_{z}+s C_{1}\right)\right]}
$$




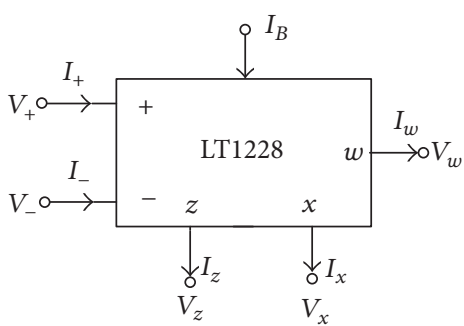

(a)

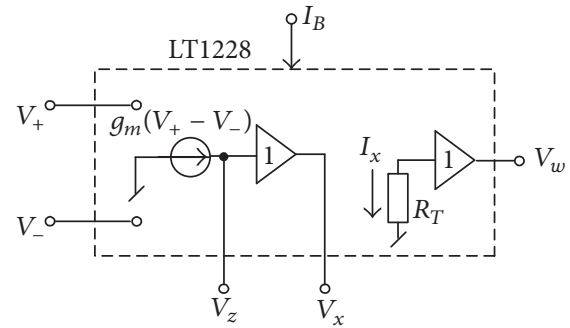

(b)

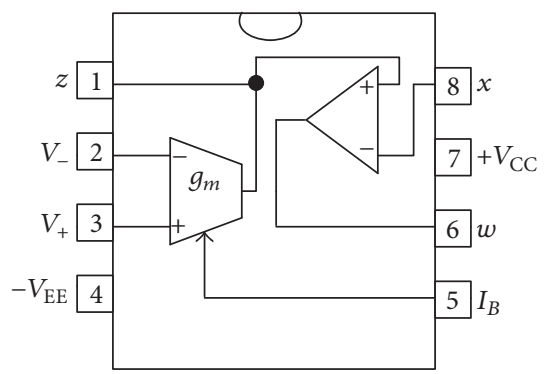

(c)

FIgURE 1: LT1228. (a) Electrical symbol of LT1228. (b) Equivalent circuit. (c) Pin configuration.

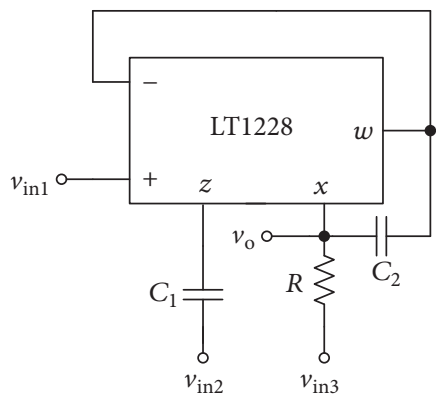

FIgure 2: Proposed filter.

where $Y_{T}=s C_{T}+G_{T}, Y_{z}=s C_{z}+G_{z}, G_{z}=1 / R_{z}, G_{T}=1 / R_{T}$, and $G=1 / R$. If the operational frequency $f_{\text {op }} \ll 1 / C_{T} R_{T}$, the output voltage in (6) becomes

$$
v_{\mathrm{o}}=\frac{s C_{2} g_{m} v_{\mathrm{in} 1}+s^{2} C_{1} C_{2} v_{\mathrm{in} 2}+g_{m} G v_{\mathrm{in} 3}}{s^{2}+s\left(\left(G_{z}+g_{m}\right) /\left(C_{1}+C_{z}\right)\right)+g_{m} G /\left(C_{1}+C_{z}\right) C_{2}} .
$$

From (7), the natural frequency is given as

$$
\omega_{0}=\sqrt{\frac{g_{m}}{\left(C_{1}+C_{z}\right) C_{2} R}} .
$$

Subsequently, the quality factor is given as

$$
Q=\frac{1}{G_{z}+g_{m}} \sqrt{\frac{\left(C_{1}+C_{z}\right) g_{m}}{C_{2} R}} .
$$

\section{Experimental Results}

In order to evaluate the performances of the proposed threeinput single-output voltage-mode multifunction filter in Figure 2, the experiment was done by using LT1228. The power supply voltage of the LT1228 was $\pm 5 \mathrm{~V}$. An experimental setup was made by taking $C_{1}=C_{2}=1 \mathrm{nF}, R=1 \mathrm{k} \Omega, I_{B}=100 \mu \mathrm{A}$. A resistor of $2 \mathrm{k} \Omega$ in series with the $x$ terminal (pin 8 of LT1228) was connected as recommended in datasheet [43]. With above component values, the natural frequency and quality factor as analyzed in (4) and (5) become $f_{0}=159.15 \mathrm{kHz}$ and $\mathrm{Q}=1$. For this test, the sinusoidal voltage with $60 \mathrm{mV}_{\mathrm{p}-\mathrm{p}}$ was applied as input voltage. The frequency response of the LP, HP, BP, and BR function is reported in Figure 3 and the phase and gain response of AP function is shown in Figure 4. It is obvious that the proposed filter can provide five filter responses as described in Section 2. The theoretical

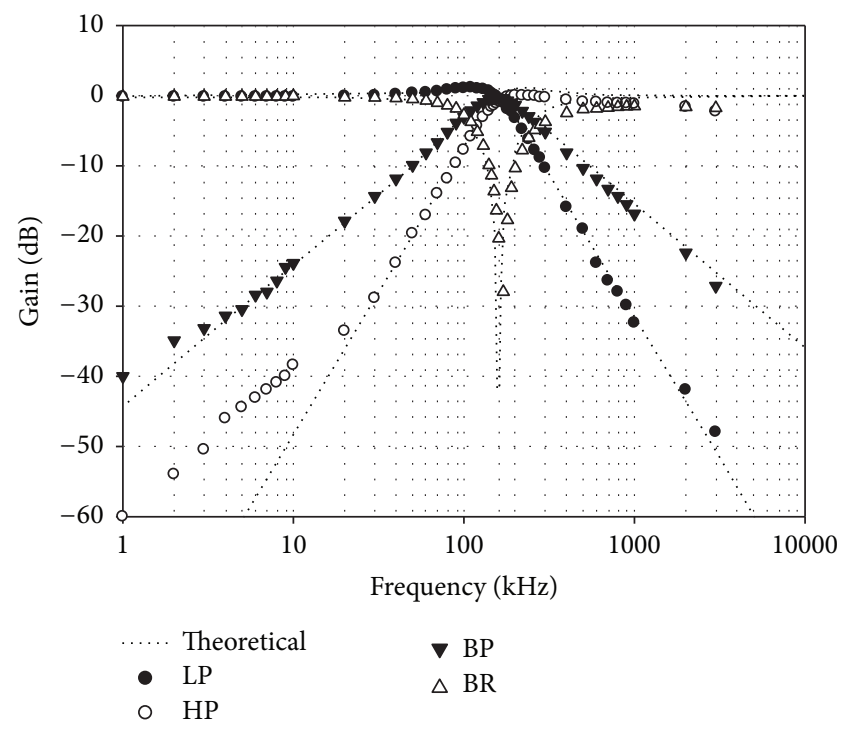

FIgURE 3: Experimental gain response of the proposed filer.

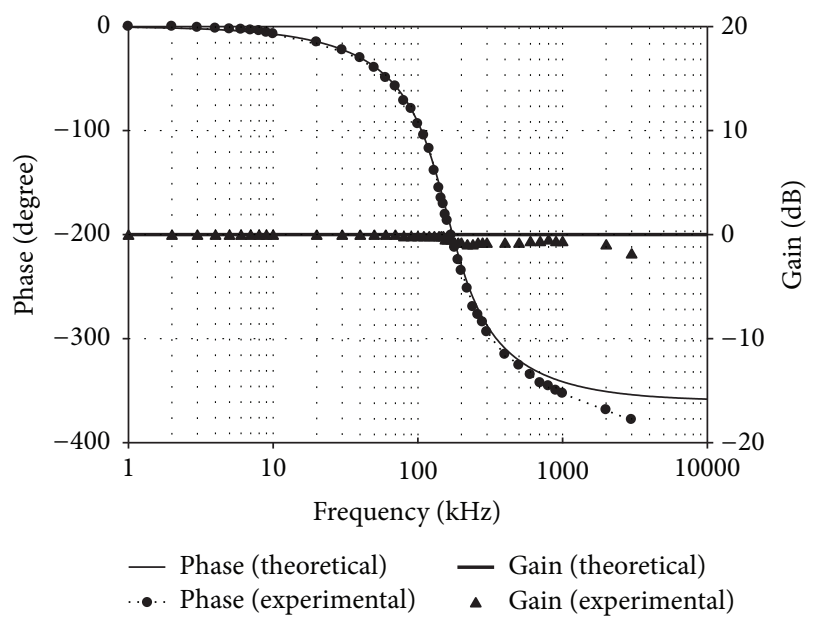

FIGURE 4: Experimental phase and gain response of all-pass function.

and experimental gain responses are slightly different during low and high frequency due to the effect of parasitic elements of LT1228 as studied in Section 2. The experimental natural frequency is about $155 \mathrm{kHz}$. The deviation of theoretical and experimental natural frequency is about $2.6 \%$. The timedomain responses of output voltage in LP, HP, BP, BR, and AP functions are, respectively, shown in Figures 5, 6, 7, 8, and 9 


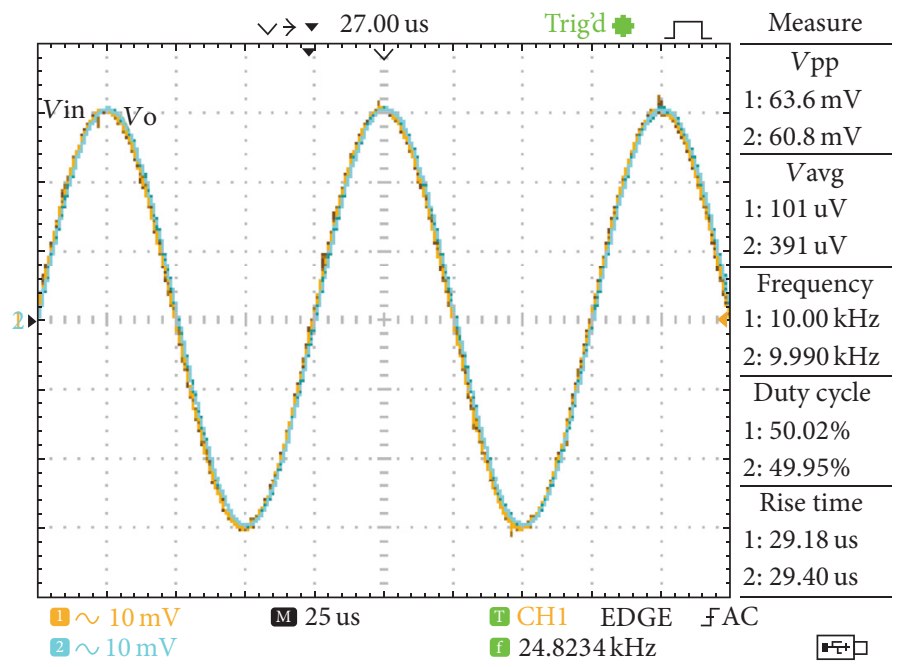

(a)

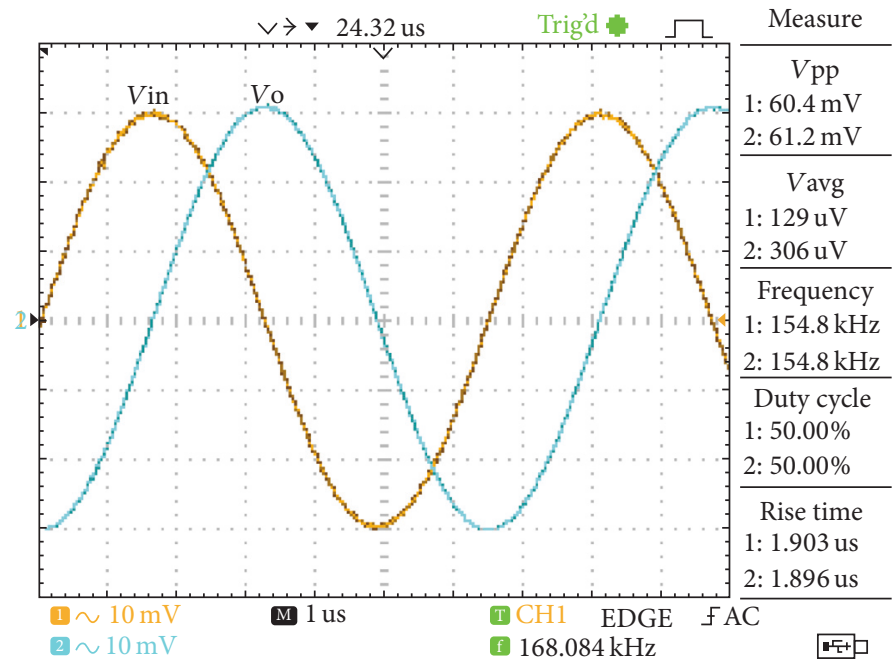

(b)

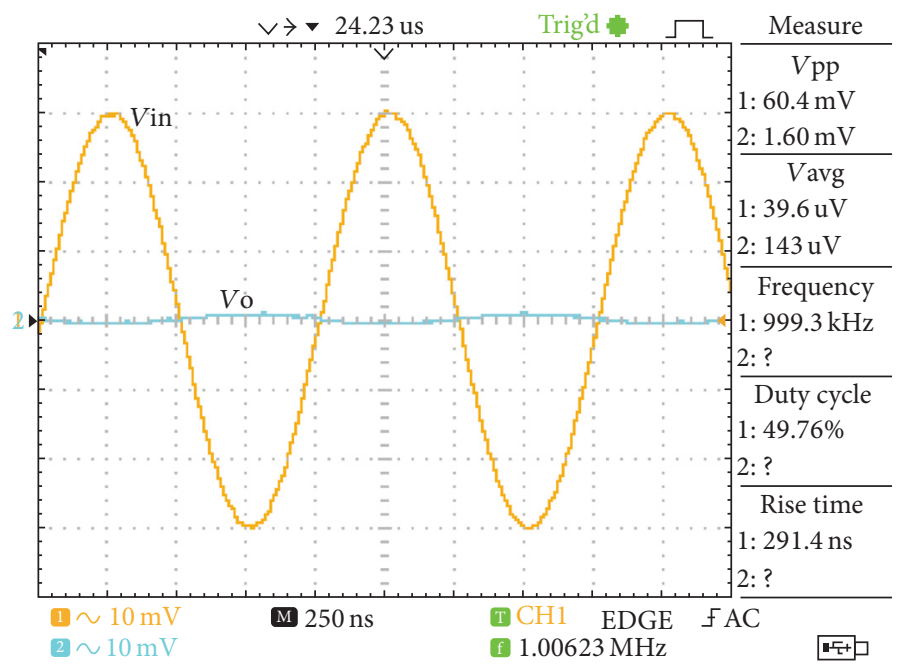

(c)

FIgURE 5: The measured input and output waveforms of low-pass filter at (a) $10 \mathrm{kHz}$, (b) $155 \mathrm{kHz}$, and (c) $1 \mathrm{MHz}$. 


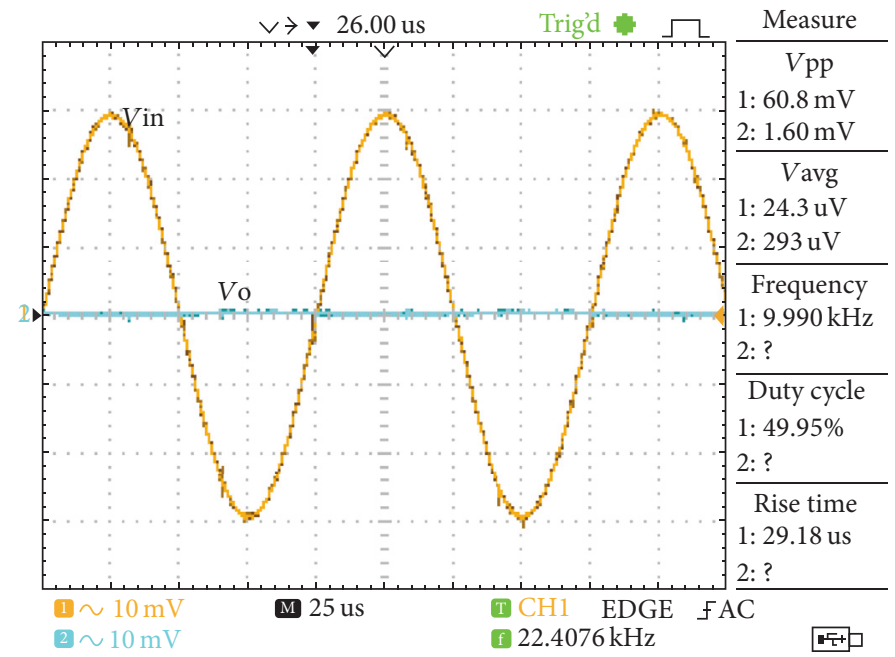

(a)

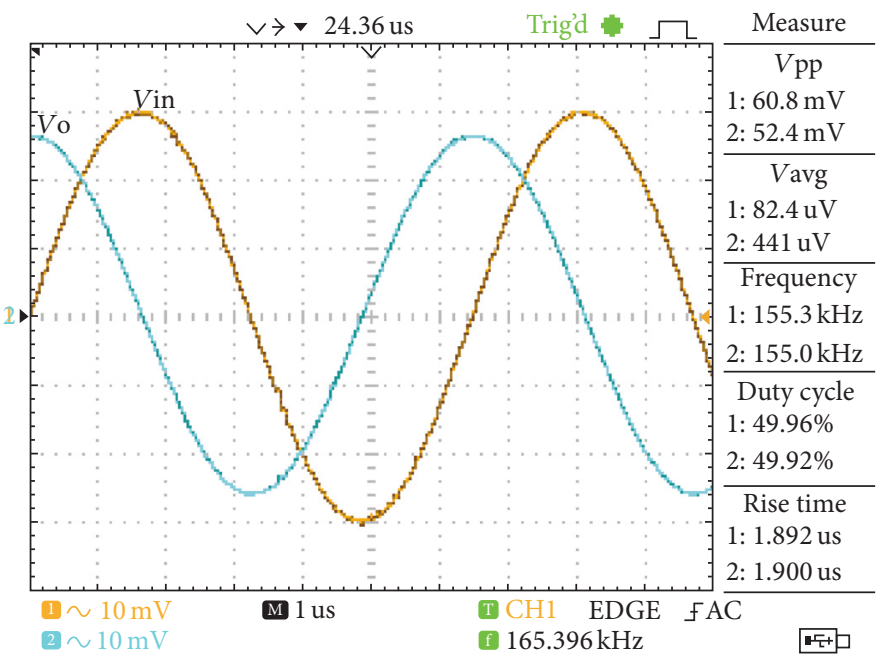

(b)

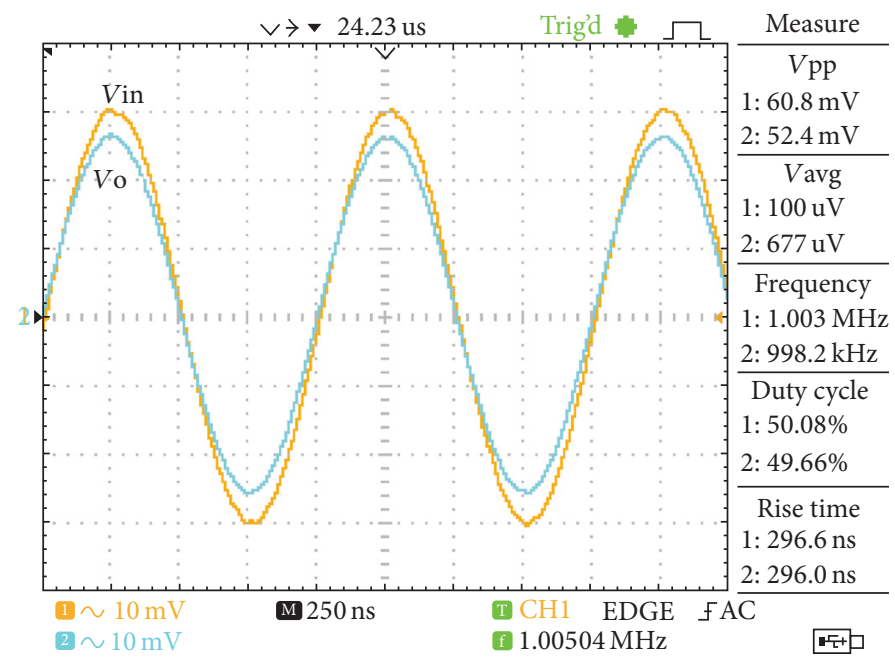

(c)

FIgURE 6: The measured input and output waveforms of high-pass filter at (a) $10 \mathrm{kHz}$, (b) $155 \mathrm{kHz}$, and (c) $1 \mathrm{MHz}$. 


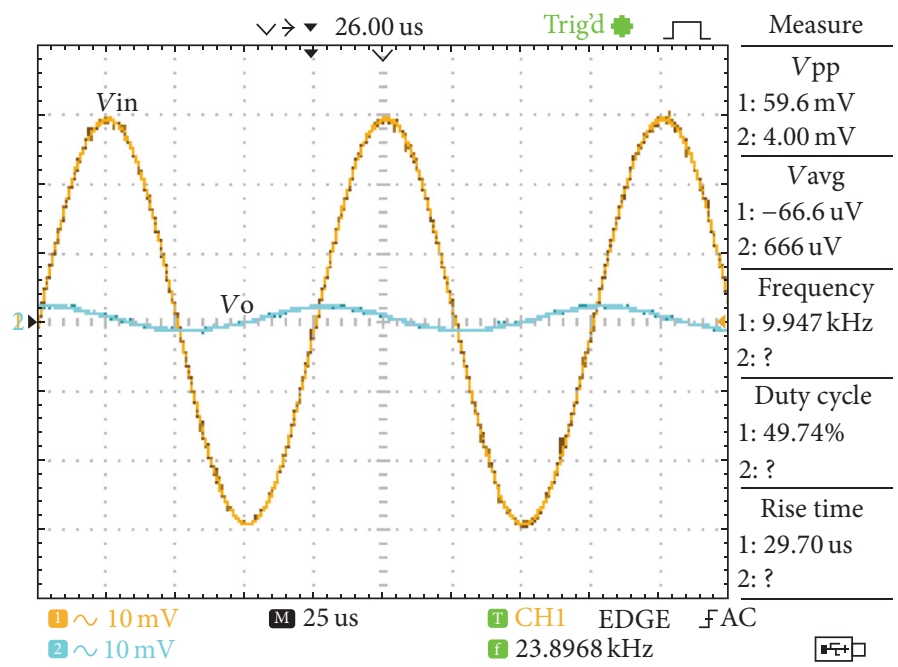

(a)

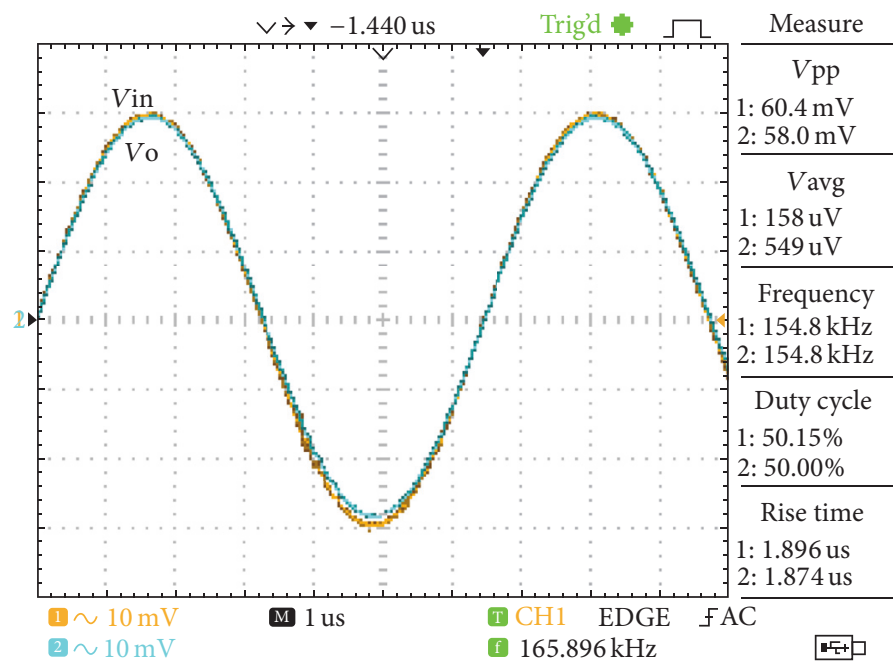

(b)

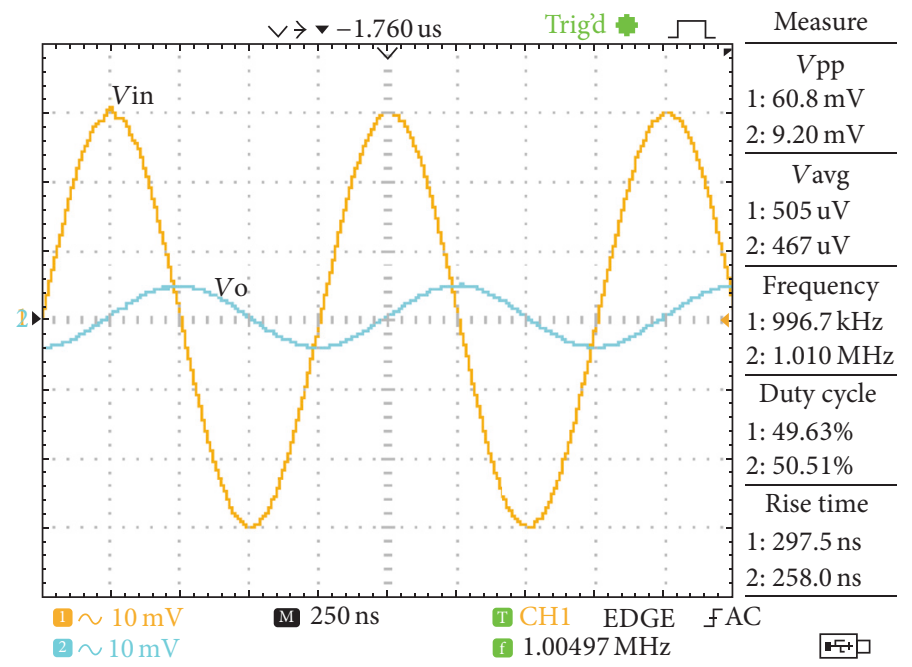

(c)

FIgURE 7: The measured input and output waveforms of band-pass filter at (a) $10 \mathrm{kHz}$, (b) $155 \mathrm{kHz}$, and (c) $1 \mathrm{MHz}$. 


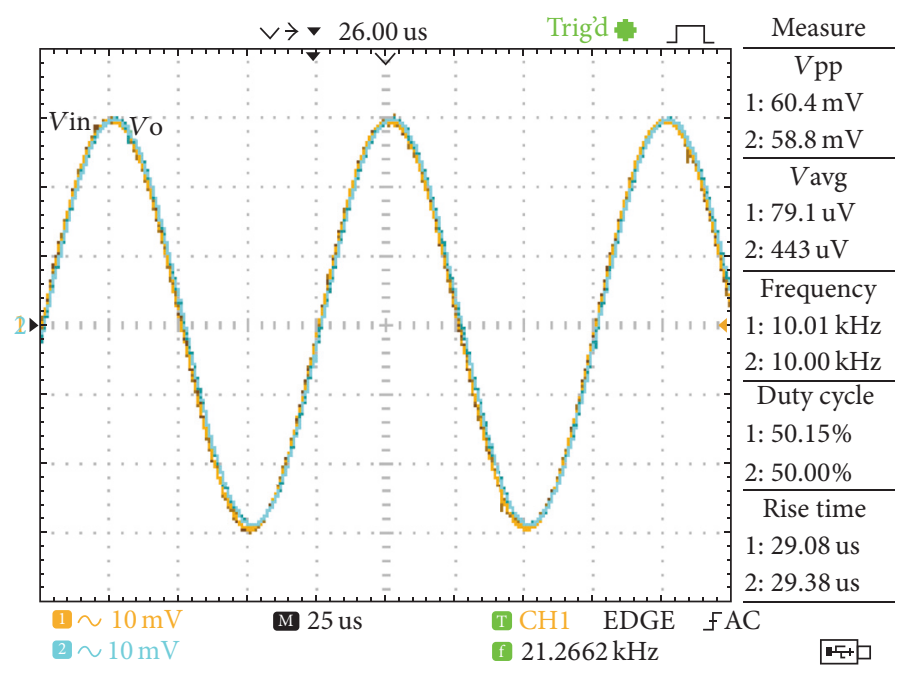

(a)

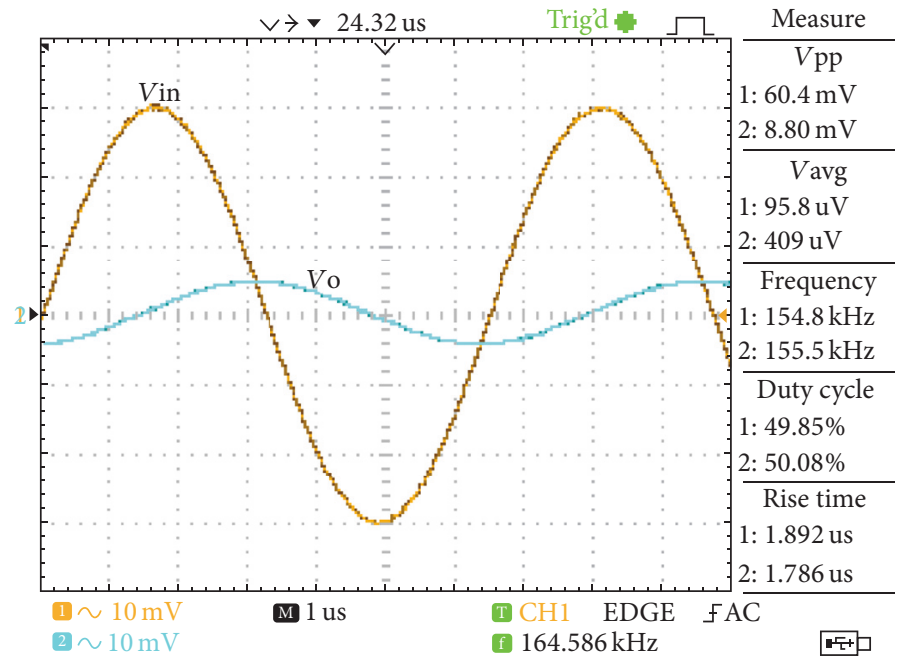

(b)

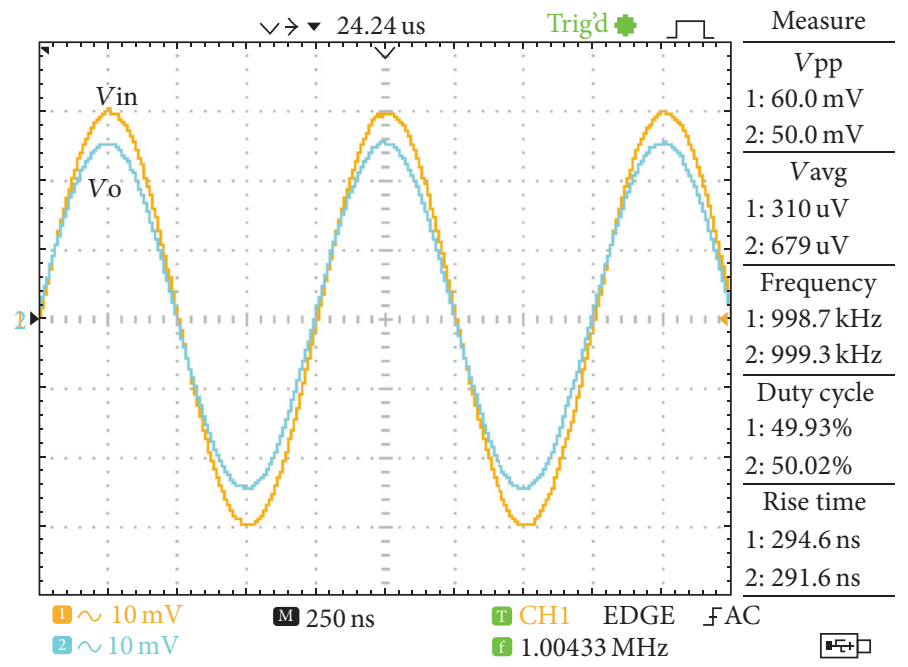

(c)

FIGURE 8: The measured input and output waveforms of band-reject filter at (a) $10 \mathrm{kHz}$, (b) $155 \mathrm{kHz}$, and (c) $1 \mathrm{MHz}$. 


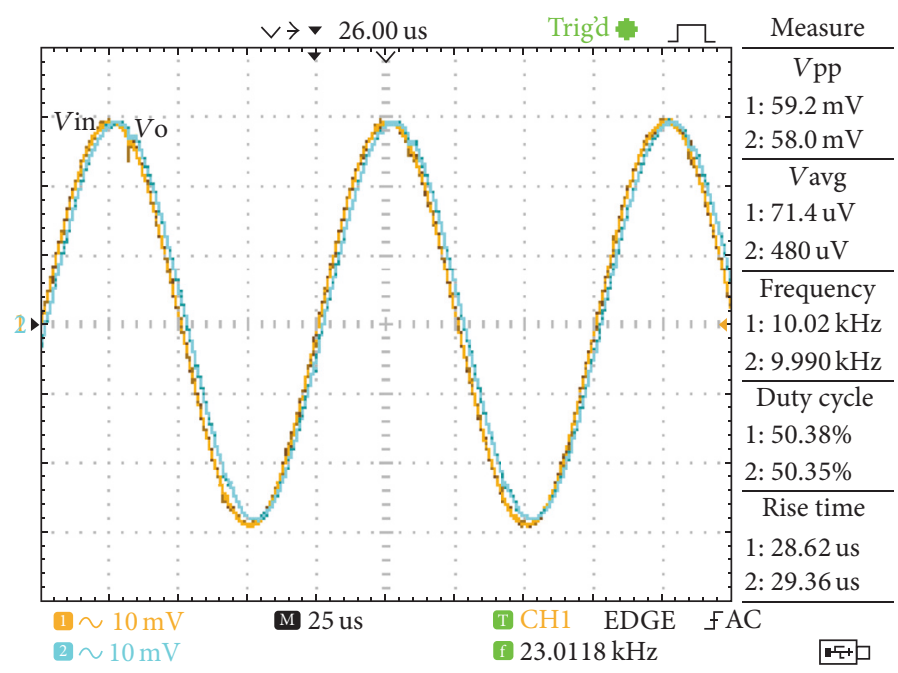

(a)

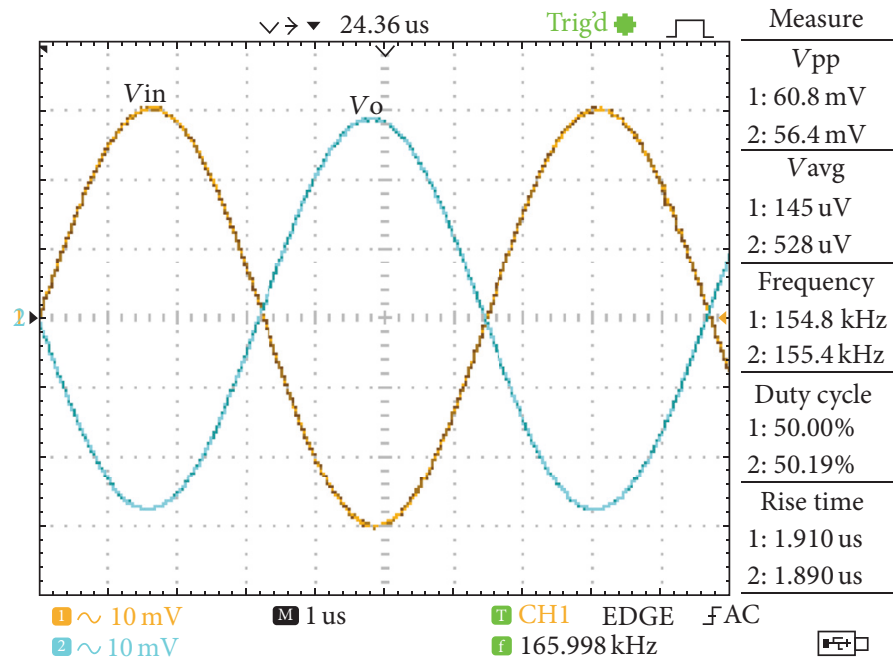

(b)

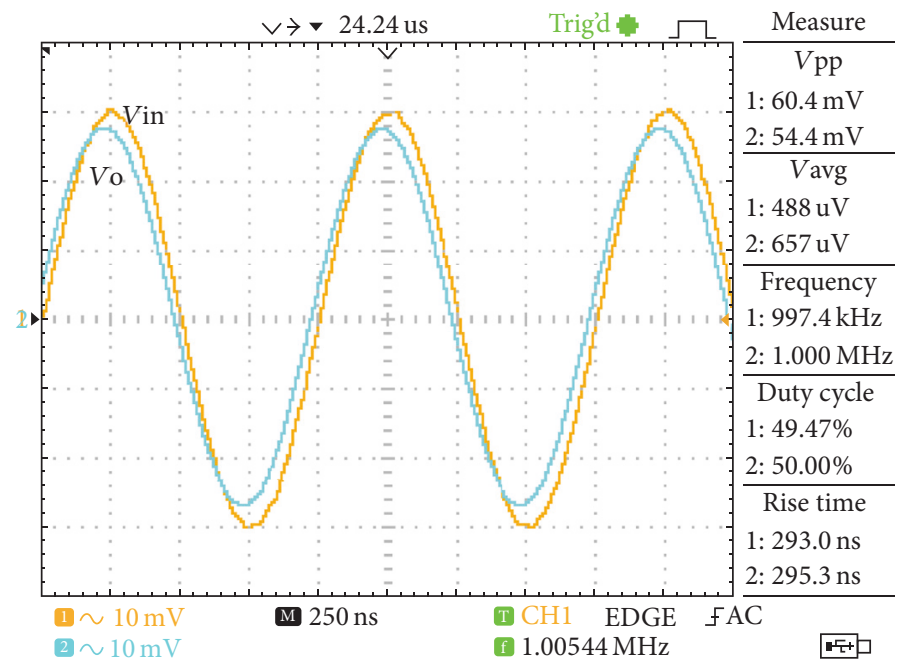

(c)

FIgURE 9: The measured input and output waveforms of all-pass filter at (a) $10 \mathrm{kHz}$, (b) $155 \mathrm{kHz}$, and (c) $1 \mathrm{MHz}$. 
when three frequencies, $10 \mathrm{kHz}, 155 \mathrm{kHz}$, and $1 \mathrm{MHz}$ with $60 \mathrm{mV}_{\mathrm{p}-\mathrm{p}}$ were applied at the input voltage.

\section{Conclusion}

In this contribution, the three-input single-output voltagemode filter is presented. The proposed filter uses only single commercially available IC, LT1228 as active element. The natural frequency and quality factor can be tuned electronically by changing the bias current of LT1228. The selection of output filter response can be done without requirement of the matching condition of passive and active component. Also, the selection of all-pass filter response can be done without the requirement of double gain amplifier. Using only single commercially available IC, the proposed filter is suitable for off-the-shelf implementation. The workability of the proposed filter is demonstrated by experimental results.

\section{Conflicts of Interest}

The authors declare that they have no conflicts of interest.

\section{Acknowledgments}

The authors are very grateful to Kasetsart University's Graduate School for funding used for publications in international academic journals.

\section{References}

[1] N. Afzal and D. Singh, "Reconfigurable mixed mode universal filter," Active and Passive Electronic Components, vol. 2014, Article ID 769198, 14 pages, 2014.

[2] P. Beg and S. Maheshwari, "Generalized filter topology using grounded components and single novel active element," Circuits, Systems, and Signal Processing, vol. 33, no. 11, pp. 36033619, 2014.

[3] W. Mekhum and W. Jaikla, "Three input single output voltagemode multifunction filter with independent control of pole frequency and quality factor," Advances in Electrical and Electronic Engineering, vol. 11, no. 6, pp. 494-500, 2013.

[4] J.-W. Horng, C.-M. Wu, and N. Herencsar, "Three-input-oneoutput current-mode universal biquadratic filter using one differential difference current conveyor," Indian Journal of Pure and Applied Physics, vol. 52, no. 8, pp. 556-562, 2014.

[5] P. Uttaphut, "New current-mode quadrature sinusoidal oscillator using single DVCCTA as active element," Przegląd Elektrotechniczny, vol. 1, no. 9, pp. 231-234, 2016.

[6] W. Jaikla, A. Noppakarn, and S. Lawanwisut, "New gain controllable resistor-less current-mode first order allpass filter and its application," Radioengineering, vol. 21, no. 1, pp. 312-316, 2012.

[7] S. Maheshwari and M. S. Ansari, "Catalog of realizations for DXCCII using commercially available ICs and applications," Radioengineering, vol. 21, no. 1, pp. 281-289, 2012.

[8] S. Maheshwari, "Current conveyor all-pass sections: brief review and novel solution," The Scientific World Journal, vol. 2013, Article ID 429391, 6 pages, 2013.

[9] R. Sotner, J. Jerabek, N. Herencsar, J.-W. Horng, K. Vrba, and T. Dostal, "Simple oscillator with enlarged tunability range based on ECCII and VGA utilizing commercially available analog multiplier," Measurement Science Review, vol. 16, no. 2, pp. 3541, 2016.

[10] C. Chang and M.-S. Lee, "Universal voltage-mode filter with three inputs and one output using three current conveyors and one voltage follower," Electronics Letters, vol. 30, no. 25, pp. 21122113, 1994.

[11] J.-W. Horng, C.-C. Tsai, and M.-H. Lee, "Novel universal voltage-mode biquad filter with three inputs and one output using only two current conveyors," International Journal of Electronics, vol. 80, no. 4, pp. 543-546, 1996.

[12] J.-W. Horng, M.-H. Lee, H.-C. Cheng, and C.-W. Chang, "New CCII-based voltage-mode universal biquadratic filter," International Journal of Electronics, vol. 82, no. 2, pp. 151-155, 1997.

[13] C.-M. Chang, "Multifunction biquadratic filters using current conveyors," IEEE Transactions on Circuits and Systems II: Analog and Digital Signal Processing, vol. 44, no. 11, pp. 956-958, 1997.

[14] C.-M. Chang and S.-H. Tu, "Universal voltage-mode filter with four inputs and one output using two CCII s," International Journal of Electronics, vol. 86, no. 3, pp. 305-309, 1999.

[15] J.-W. Horng, "High-input impedance voltage-mode universal biquadratic filter using three plus-type CCIIs," IEEE Transactions on Circuits and Systems II: Analog and Digital Signal Processing, vol. 48, no. 10, pp. 996-997, 2001.

[16] J.-W. Horng, "Voltage-mode multifunction filter using one current feedback amplifier and one voltage follower," International Journal of Electronics, vol. 88, no. 2, pp. 153-157, 2001.

[17] J.-W. Horng, C.-K. Chang, and J.-M. Chu, "Voltage-mode universal biquadratic filter using single current-feedback amplifier," IEICE Transactions on Fundamentals of Electronics, Communications and Computer Sciences, vol. 85, no. 8, pp. 19701973, 2002.

[18] J.-W. Horng, "High input impedance voltage-mode universal biquadratic filter using two OTAs and one CCII," International Journal of Electronics, vol. 90, no. 3, pp. 185-191, 2003.

[19] C.-M. Chang and H.-P. Chen, "Universal capacitor-grounded voltage-mode filter with three inputs and a single output," International Journal of Electronics, vol. 90, no. 6, pp. 401-406, 2003.

[20] J.-W. Horng, "Voltage-mode universal biquadratic filter using two OTAs," Active and Passive Electronic Components, vol. 27, no. 2, pp. 85-89, 2004.

[21] J.-W. Horng, "High input impedance voltage-mode universal biquadratic filters with three inputs using plus-type CCIIs," International Journal of Electronics, vol. 91, no. 8, pp. 465-475, 2004.

[22] J. W. Horng, "Voltage-mode universal biquadratic filters using CCIIs," IEICE Transactions on Fundamentals of Electronics, Communications and Computer Sciences, vol. 87, pp. 406-409, 2004.

[23] N. A. Shah and M. A. Malik, "Voltage/current-mode universal filter using FTFN and CFA," Analog Integrated Circuits and Signal Processing, vol. 45, no. 2, pp. 197-203, 2005.

[24] C.-M. Chang and H.-P. Chen, "Single FDCCII-based tunable universal voltage-mode filter," Circuits, Systems, and Signal Processing, vol. 24, no. 2, pp. 221-227, 2005.

[25] N. A. Shah, M. F. Rather, and S. Z. Iqbal, "A novel voltage-mode universal filter using a single CFA," Active and Passive Electronic Devices, vol. 1, pp. 183-188, 2005. 
[26] M. Sagbas and M. Koksal, "Voltage-mode three-input singleoutput multifunction filters employing minimum number of components," Frequenz, vol. 61, no. 3-4, pp. 87-93, 2007.

[27] W.-Y. Chiu and J.-W. Horng, "High-input and low-output impedance voltage-mode universal biquadratic filter using DDCCs," IEEE Transactions on Circuits and Systems II: Express Briefs, vol. 54, no. 8, pp. 649-652, 2007.

[28] S. Kilinç, A. Ü. Keskin, and U. Çam, "Cascadable voltage-mode multifunction biquad employing single OTRA," Frequenz, vol. 61, no. 3-4, pp. 84-86, 2007.

[29] M. Kumngern, M. Somdunyakanok, and P. Prommee, "Highinput impedance voltage-mode multifunction filter with threeinput single-output based on simple CMOS OTAs," in Proceedings of the International Symposium on Communications and Information Technologies (ISCIT '08), pp. 426-431, October 2008.

[30] H.-P. Chen and Y.-Z. Liao, "High-input and low-output impedance voltage-mode universal biquadratic filter using FDCCIIs," in Proceedings of the 9th International Conference on Solid-State and Integrated-Circuit Technology (ICSICT '08), pp. 1794-1798, October 2008.

[31] N. Herencsar, J. Koton, and K. Vrba, "Single CCTA-based universal biquadratic filters employing minimum components," International Journal of Computer and Electrical Engineering, vol. 1, no. 3, pp. 307-310, 2009.

[32] H.-P. Chen, "Voltage-mode FDCCII-based universal filters," AEU-International Journal of Electronics and Communications, vol. 62, no. 4, pp. 320-323, 2008.

[33] W. Tangsrirat, "Novel current-mode and voltage-mode universal biquad filters using single CFTA," Indian Journal of Engineering and Materials Sciences, vol. 17, no. 2, pp. 99-104, 2010.

[34] A. Ranjan and S. K. Paul, "Voltage mode universal biquad using CCCII," Active and Passive Electronic Components, vol. 2011, Article ID 439052, 5 pages, 2011.

[35] I. Myderrizi, S. Minaei, and E. Yuce, "DXCCII-based grounded inductance simulators and filter applications," Microelectronics Journal, vol. 42, no. 9, pp. 1074-1081, 2011.

[36] W. Tangsrirat and O. Channumsin, "Voltage-mode multifunctional biquadratic filter using single DVCC and minimum number of passive elements," Indian Journal of Pure and Applied Physics, vol. 49, no. 10, pp. 703-707, 2011.

[37] J. Satansup and W. Tangsrirat, "Single VDTA-based voltagemode electronically tunable universal filter," in Proceedings of the 27th International Technical Conference on Circuits/Systems, Computers and Communications, Sapporo, Japan, July 2012.

[38] J.-W. Horng, C.-H. Hsu, and C.-Y. Tseng, "High input impedance voltage-mode universal biquadratic filters with three inputs using three CCs and grounding capacitors," Radioengineering, vol. 21, no. 1, pp. 290-296, 2012.

[39] J. K. Pathak, A. K. Singh, and R. Senani, "New Voltage Mode Universal Filters Using Only Two CDBAs," ISRN Electronics, vol. 2013, Article ID 987867, 6 pages, 2013.

[40] K. L. Pushkar, D. R. Bhaskar, and D. Prasad, "A new MISO-type voltage-mode universal biquad using single VD-DIBA," ISRN Electronics, vol. 2013, Article ID 478213, 5 pages, 2013.

[41] W. Ninsraku, D. Biolek, W. Jaikla, S. Siripongdee, and P. Suwanjan, "Electronically controlled high input and low output impedance voltage mode multifunction filter with grounded capacitors," AEU-International Journal of Electronics and Communications, vol. 68, no. 12, pp. 1239-1246, 2014.
[42] S. Sangyaem, S. Siripongdee, W. Jaikla, and F. Khateb, "Fiveinputs single-output voltage mode universal filter with high input and low output impedance using VDDDAs," International Journal for Light and Electron Optics, vol. 128, pp. 14-25, 2017.

[43] http://www.linear.com/product/LT1228.

[44] S. Siripongdee and W. Jaikla, "Electronically controllable grounded inductance simulators using single commercially available IC: LT1228," AEU-International Journal of Electronics and Communications, 2017. 


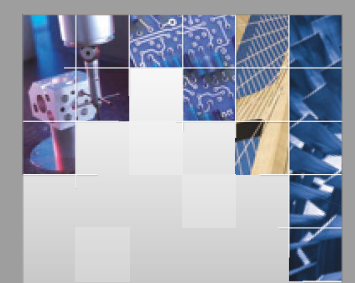

\section{Enfincering}
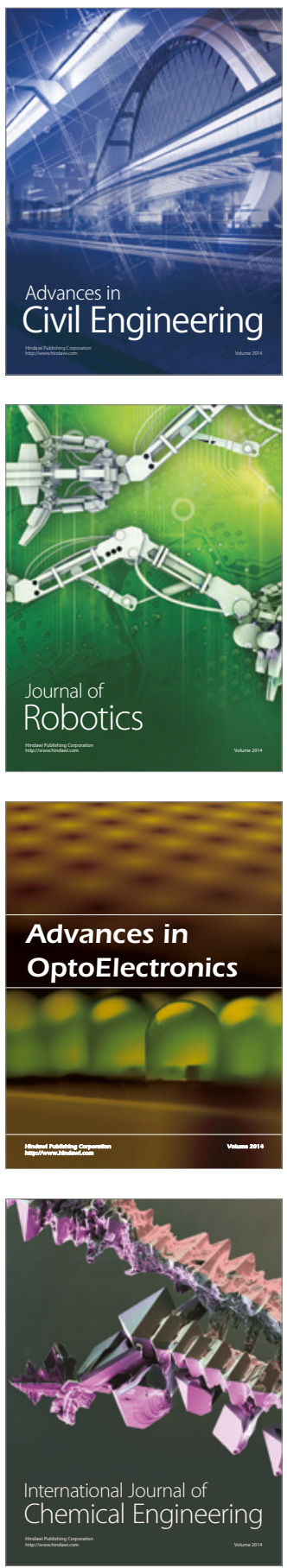

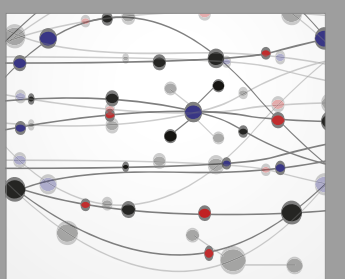

The Scientific World Journal

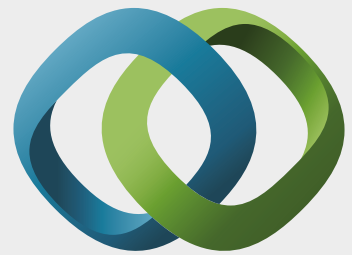

\section{Hindawi}

Submit your manuscripts at

https://www.hindawi.com
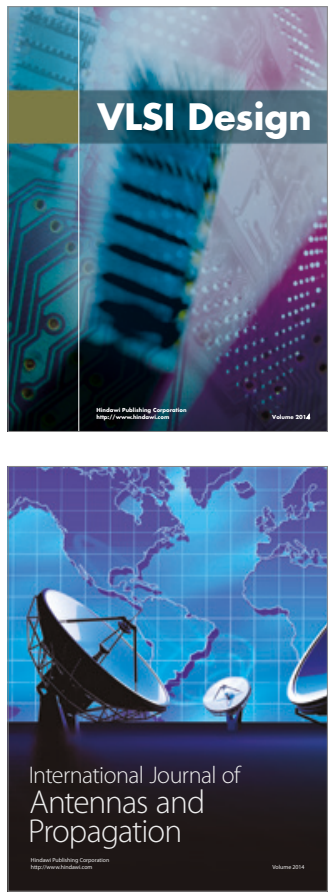

\section{Rotating}

Machinery
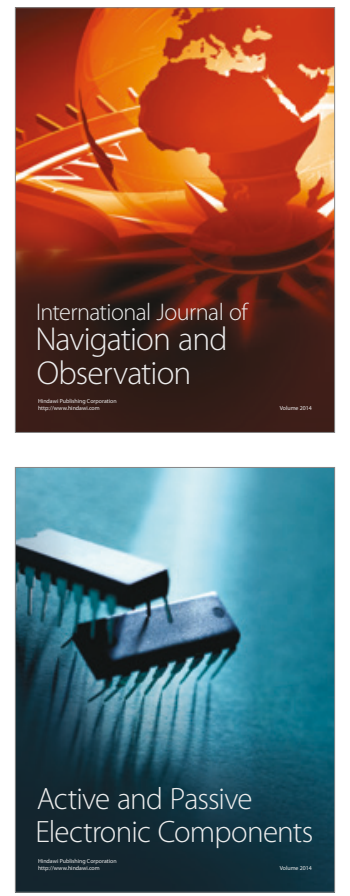
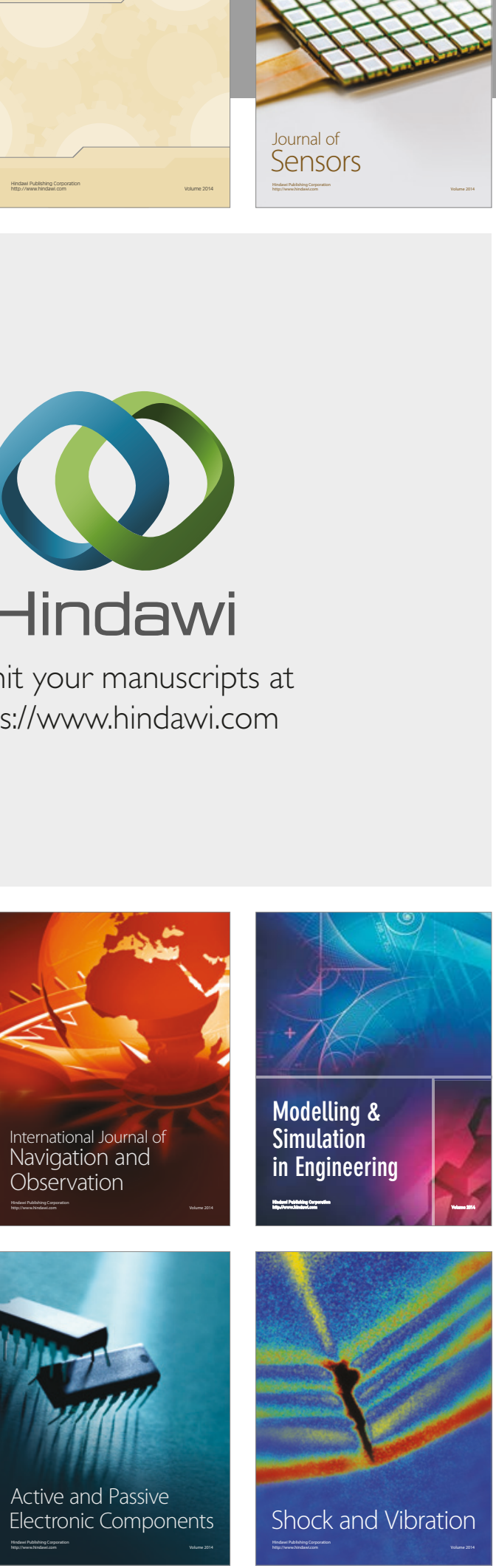
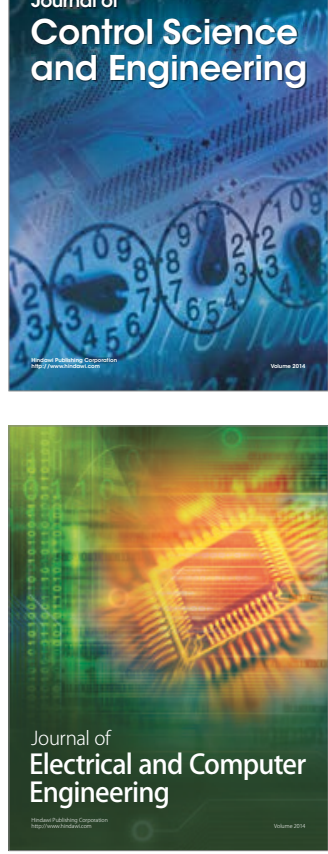

Distributed

Journal of

Control Science

and Engineering
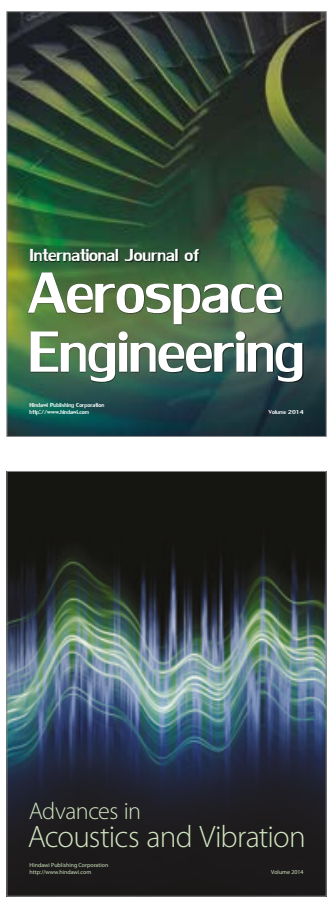

Sensor Networks 